\title{
Gastric Outlet Obstruction by a Hydrocholecyst. A Very Rare Variant of Bouveret Syndrome: A Case Report
}

\author{
${ }^{1}$ General Surgery Department, Hospital Español, Mexico City, Mexico \\ ${ }^{2}$ Gastroenterology Department, Hospital Español, Mexico City, Mexico \\ ${ }^{3}$ Geriatric Medicine Department, Hospital Español, Mexico City, Mexico \\ Email: *luis13betancourt@gmail.com
}

Luis Daniel Betancourt Martínez ${ }^{1^{*}}$ (D), Alberto Manuel González Chávez ${ }^{1}$ (i), Mario Andrés González Chávez ${ }^{1}$, Jiroyoshi Enrique Muneta Kishigami², Abraham Samra Saad ${ }^{3}$

How to cite this paper: Martínez, L.D.B. Chávez, A.M.G., Chávez, M.A.G., Kishigami, J.E.M. and Saad, A.S. (2021) Gastric Outlet Obstruction by a Hydrocholecyst. A Very Rare Variant of Bouveret Syndrome: A Case Report. Surgical Science, 12, 332-337. https://doi.org/10.4236/ss.2021.129034

Received: July 22, 2021

Accepted: September 27, 2021

Published: September 30, 2021

Copyright $\odot 2021$ by author(s) and Scientific Research Publishing Inc. This work is licensed under the Creative Commons Attribution International License (CC BY 4.0).

http://creativecommons.org/licenses/by/4.0/

\begin{abstract}
It is estimated that between $0.3 \%-0.5 \%$ of patients with cholelithiasis have biliary ileus, of this small proportion, only between $1 \%-3 \%$ is complicated by the syndrome described in 1896 by Leon Bouveret. Bouveret syndrome refers to the obstruction of the gastric outlet tract secondary to the passage and impactation of a gallstone in the duodenum, through a cholecystoduodenal fistula. It is most common in women, between the ages of $74-77$ and is clinically characterized by pain, bloating, incoercible vomiting and anorexia.
\end{abstract}

\section{Keywords}

Bouveret Syndrome, Gastric Outlet Obstruction, Gallstone, Hydrocholecyst, Cholelithiasis, Gastromegaly

\section{Introduction}

Gallstone disease is a common pathology in the general population with a high prevalence in western countries. Only between $0.3 \%-0.5 \%$ of patients with cholelithiasis will present with gallstone ileus, and of this small proportion, only between $1 \%$ and 3\%, will be complicated by the syndrome described in 1896 by Leon Bouveret [1]. Bouveret's syndrome is a form of gastric outlet obstruction, secondary to the passage and impaction of a gallstone in the duodenum through a cholecystoduodenal fistula [2]. It is more frequent in women between $74-77$ years of age and is clinically characterized by pain, bloating, incoercible vomiting and anorexia [1]. 


\section{Case Report}

We present the case of an 82-year-old woman, with no relevant history, who consulted in the ER for a four-day episode of colic-like pain located in the upper quadrants of the abdomen, accompanied by nausea without vomiting and obstipation. The physical examination documented supraumbilical bloating, timpanism with decreased peristalsis, without any signs of peritoneal irritation. The laboratory tests results showed systemic inflammatory response as well as elevation of liver and pancreatic enzymes (Table 1).

Abdominal x-rays revealed gastromegaly with abundant waste material in the stomach. An abdominal CT scan with intravenous contrast was requested and showed signs of an apparent blockage of the gastric outlet tract with dilatation of the gallbladder and common bile duct (Figure 1).

A nasogastric tube was placed to empty the stomach, unsuccessfully, so a panendoscopy was requested to obtain gastric evacuation and explore for the cause of obstruction (Figure 2). The study documented peptic ulcers located in the major curvature of the stomach and the second part of the duodenum, but nothing explained the obstruction. A magnetic resonance cholangiography was subsequently requested to rule out a biliopancreatic tumor, reporting a $12 \mathrm{~mm}$ common bile duct, as well as dilatation of the stomach, gallbladder and duodenum, but without apparent cause (Figure 3).

Table 1. Laboratory test results of the patient.

\begin{tabular}{ll}
\hline \multicolumn{1}{c}{ Test } & \multicolumn{1}{c}{ Result } \\
\hline Blood Count & WBC $8.2 \times 10^{3} / \mathrm{uL}$, Bands $31 \% \mathrm{Hb} 11.9 \mathrm{~g} / \mathrm{dL}$ Platelets $306 \times 10^{3} / \mathrm{uL}$ \\
Liver Function & AST 68.9 IU/L, ALT 116.5 IU/L, GGT 75.6 IU/L, Alkaline Phosphatase 247 \\
Serum Electrolytes & $\mathrm{Na} 121.9 \mathrm{mmol} / \mathrm{L} \mathrm{K} 4.75 \mathrm{mmol} / \mathrm{L} \mathrm{Cl} 91.8 \mathrm{mmol} / \mathrm{L}$ \\
BUN, Cr & BUN $29.6 \mathrm{mg} / \mathrm{dL} \mathrm{Cr} 1.0 \mathrm{mg} / \mathrm{dL}$ \\
\hline
\end{tabular}

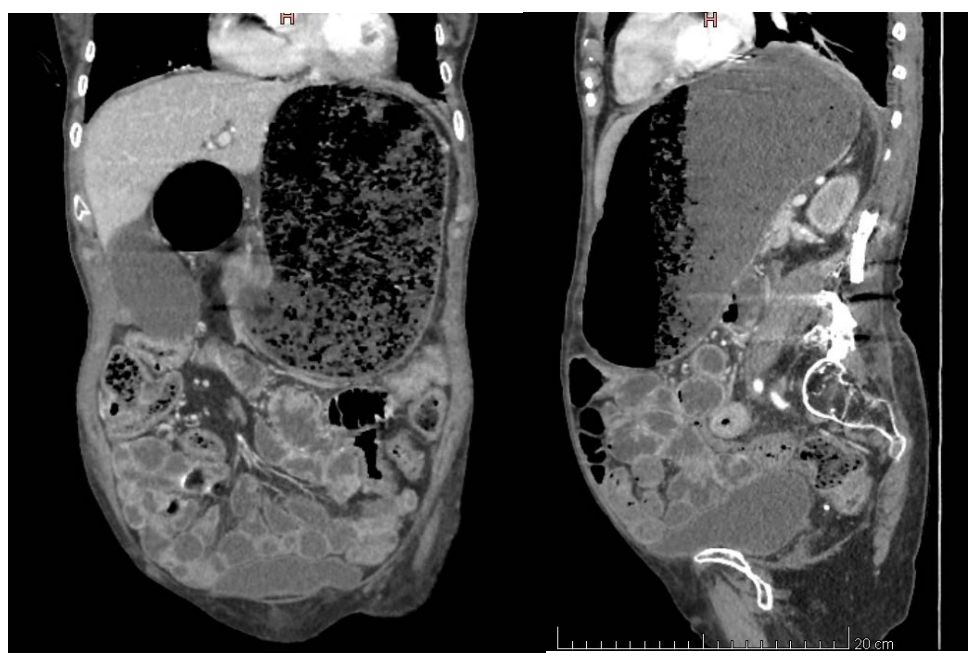

Figure 1. Contrasted computed tomography showing gallbladder dilatation and gastromegaly. 


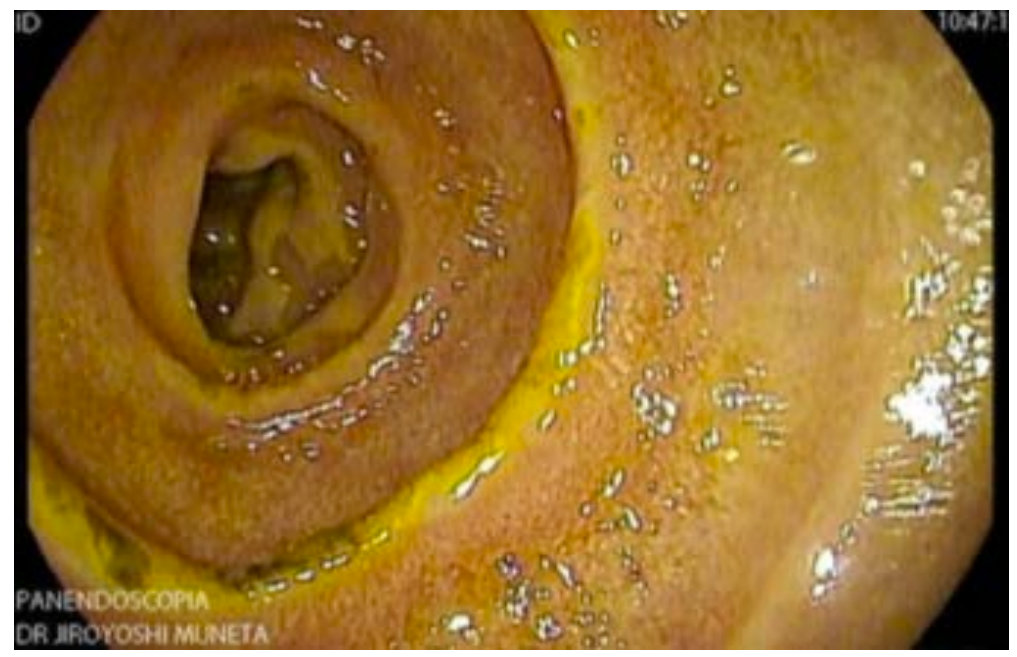

Figure 2. Endoscopic view of the interior of the duodenum demonstrating the absence of intrinsic causes for gastric outlet obstruction.

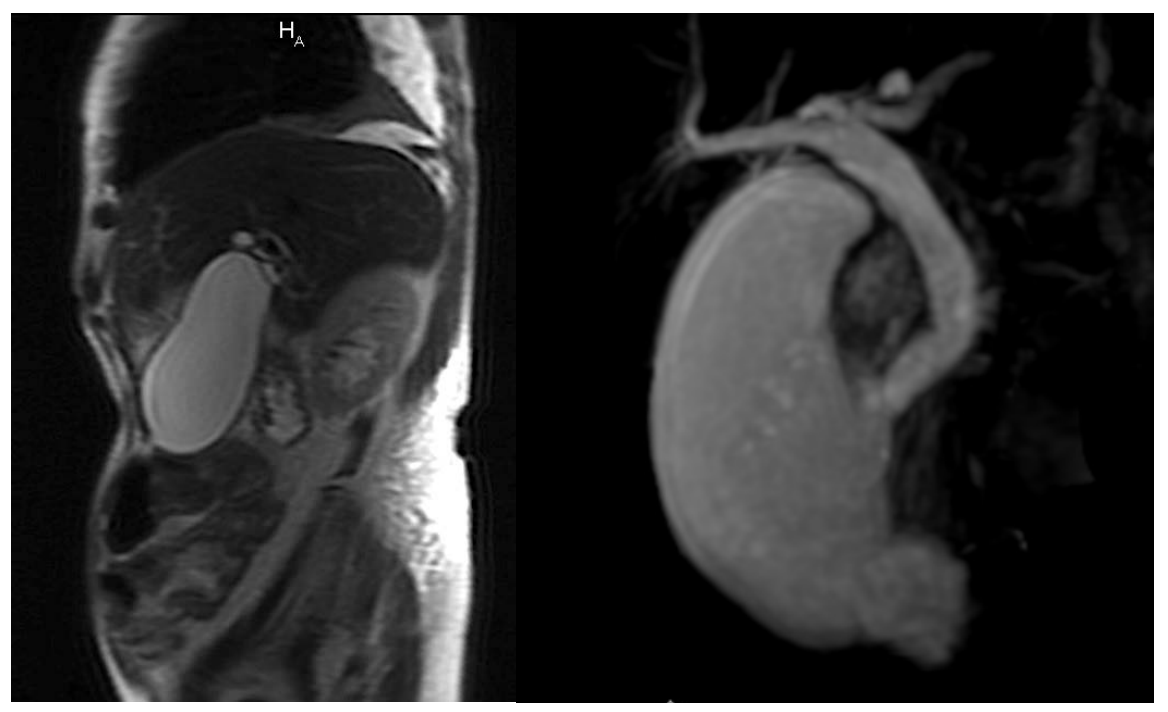

Figure 3. Magnetic resonance imaging demonstrating extrinsic compression of duodenum by a dilated gallbladder. Common bile duct without alterations.

In subsequent laboratory tests, pancreatic enzymes were normal and all tumor markers were negative. Finally, an abdominal ultrasound was performed in which the gallbladder measured $11.5 \times 5 \times 6 \mathrm{~mm}$, with a thick wall, abundant internal biliary sludge and a common bile duct of $15 \mathrm{~mm}$ in diameter. A hydrocholecyst was diagnosed, so the patient underwent a laparoscopic cholecystectomy (Figure 4).

The gallbladder was punctured at the beginning of the procedure, obtaining $200 \mathrm{ml}$ of clear bile (Figure 5). By the end of the procedure, the distention of the upper abdomen had decreased considerably. During the next few days, the patient showed clear signs of improvement with pain remission, audible bowel sounds, tolerance to oral food intake and presence of evacuations, so it was decided to discharge. 


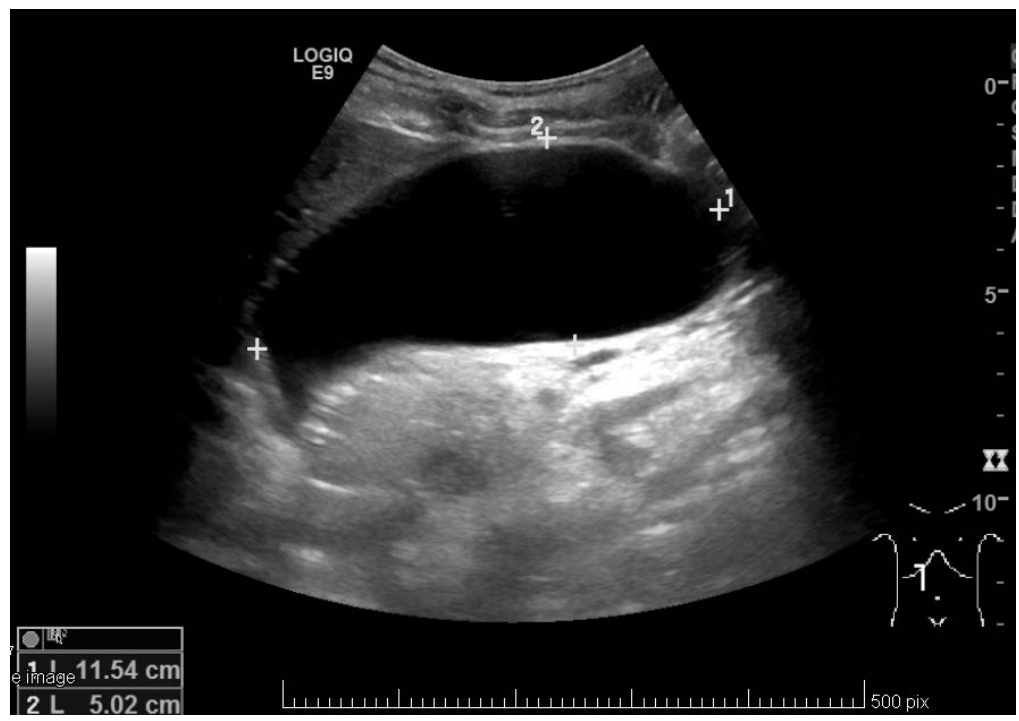

Figure 4. Ultrasound with gallbladder measurements, compatible with a hydrocholecyst.

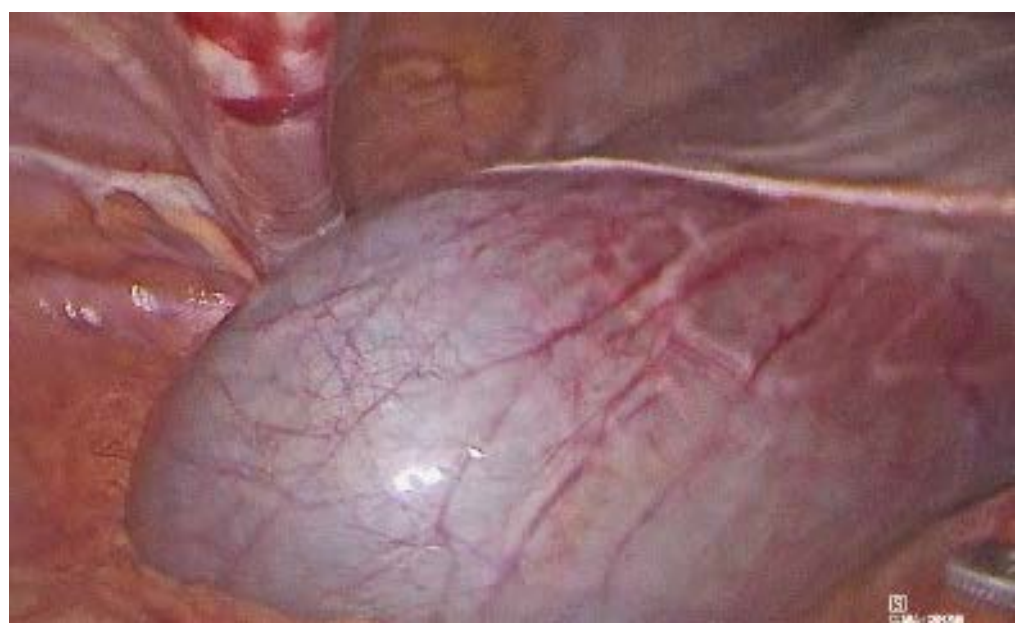

Figure 5. Enlarged gallbladder during surgery, showing signs of hydrocholecyst compressing the duodenum.

\section{Discussion}

Currently the most common cause of gastric outlet obstruction is pancreatic carcinoma, before 1970 until the advent of the H2 blockers, the most common cause was peptic ulcer disease [3]. Bouveret Syndrome is a very rare cause of gastric outlet obstruction and is usually associated with the presence of a giant gallstone $(>2 \mathrm{~cm})$ and a cholecystoduodenal fistula. In essence, it is the lithiasic pathology of the gallbladder that obstructs the outlet tract, causing gastromegaly and the typical symptoms of the syndrome: abdominal pain, bloating, vomit and early satiety [4]. Our case was not associated with fistulas or giant gallstones, but produced gastromegaly and the usual signs of Bouveret Syndrome, because of a cholelithiasic state, specifically, that caused the extrinsic compression from a hydrocholecyst produced in the second part of the duodenum. The most common cause for the appearance of a hydrocholecyst is mechanical obstruction of 
Table 2. The six cases of the variant described of Bouveret Syndrome.

\begin{tabular}{cccccc}
\hline Author & Year & Patient & Age & Resolution & Country \\
\hline Katsinelos, P et al. [6] & 2000 & - & - & Cholecystectomy & Greece \\
Das, N et al. [7] & 2003 & Female & 74 years old & Cholecystectomy & Ireland \\
Berretti, D et al. [8] & 2012 & Male & 72 years old & Cholecystectomy & Italy \\
Loh, W.L et al. [9] & 2019 & Male & 63 years old & Cholecystectomy & Singapore \\
Murthi, M et al. [10] & 2019 & Male & 59 years old & Cholecystectomy & India \\
Betancourt, L. D et al. & 2020 & Female & 82 years old & Cholecystectomy & Mexico \\
\hline
\end{tabular}

cystic duct by a gallstone, which prevents the gallbladder from filling retrogradely. The bile salts are absorbed and the mucus-producing glands fill the gallbladder with its secretion. The gallbladder can store up to $1.5 \mathrm{~L}$ of fluid and its weight can block the duodenum [5].

It is important to note that, when faced with an obstruction of the gastroduodenal outlet tract, we must rule out the presence of a biliopancreatic tumor (cancer of the head of the pancreas, mainly). That explains a lot about the approach followed in this particular case of an 82-year-old woman. Prior to the use of $\mathrm{H} 2$ blockers, peptic stenosis was the most common cause of this blockage.

\section{Conclusions}

Bouveret syndrome is a rare cause of gastric outlet tract obstruction, it is usually caused by a large gallstone that reaches the digestive tract through a cholecystoduodenal fistula. The symptoms are usually non-specific. The diagnosis and management should be multidisciplinary including surgery, radiology and endoscopy. This case was not associated with fistulas or gallstones, but by a hydrocholecyst that caused extrinsic compression in the second part of the duodenum.

To our knowledge, this is the sixth case reported in the world literature (Table 2) about an extremely rare variant, of an extremely rare syndrome.

\section{Conflicts of Interest}

The authors declare no conflicts of interest regarding the publication of this paper.

\section{References}

[1] Cappell, M.S. and Davis, M. (2006) Characterization of Bouveret's Syndrome: A Comprehensive Review of 128 Cases. American Journal of Gastroenterology, 101, 2139-2146. https://doi.org/10.1111/j.1572-0241.2006.00645.x

[2] Kudaravalli, P., Saleem, S.A., Goodman, A., Pendela, V.S. and Arif, M.O. (2020) Bouveret Syndrome as a Rare Cause of Gastric Outlet Obstruction. Proceedings Baylor University Medical Center, 33, 235-236. https://doi.org/10.1080/08998280.2019.1708841

[3] Koop, A.H., Palmer, W.C. and Stancampiano, F.F. (2019) Gastric Outlet Obstruc- 
tion: A Red Flag, Potentially Manageable. Cleveland Clinic Journal of Medicine, 86, 345-353. https://doi.org/10.3949/ccjm.86a.18035

[4] Alemi, F., Seiser, N. and Ayloo, S. (2019) Gallstone Disease: Cholecystitis, Mirizzi Syndrome, Bouveret Syndrome, Gallstone Ileus. Surgical Clinics of North America, 99, 231-244. https://doi.org/10.1016/j.suc.2018.12.006

[5] Jones, M.W. and Deppen, J.G. (2021) Gallbladder Mucocele. In: StatPearls [Internet], StatPearls Publishing, Treasure Island, FL. https://www.ncbi.nlm.nih.gov/books/NBK513282/

[6] Katsinelos, P., Kalomenopoulou, M., Katsiba, D., Christopoulos, S., Dimiropoulos, S., Chris-Todoulou, K. and Eugenidis, N. (2000) Gastric Outlet Obstruction due to Benign Dilatation of Gallbladder. Endoscopy, 32, S70.

[7] Das, N., Lee, J., Date, R., Panesar, K.J.S. and Reilly, M. (2003) Gall Bladder Distension Causing Gastric Outlet Obstruction: A Variant of Bouveret's Syndrome. European Journal of Radiology Extra, 46, 116-118.

https://doi.org/10.1016/S1571-4675(03)00060-9

[8] Berretti, D., Checchin, D., Pevere, S., Marino, M., Panos, J., Lodolo, I., et al. (2012) P. 14.21 Gallbladder Distension Causing Gastric Outlet Obstruction; A Variant of Bouveret's Syndrome Diagnosed by Endoscopic Ultrasonography. Digestive and Liver Disease, 44, S183. https://doi.org/10.1016/S1590-8658(12)60516-7

[9] Loh, W.L., Ng, N.Z.P., Kabir, T. and Chan, C.Y. (2019) Rare Case of Gallbladder Mucocele Causing Gastric Outlet Obstruction Treated with Cholecystectomy. International Journal of Surgery Case Reports, 57, 84-87.

https://doi.org/10.1016/j.ijscr.2019.03.013

[10] Murthi, M. and Murali, R. (2019) The Elephant in the Room: A Rare Cause of Gastric Outlet Obstruction: 1319. American Journal of Gastroenterology, 114, S731. https://doi.org/10.14309/01.ajg.0000594804.58963.f7 